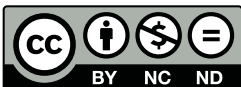

Estudos Teológicos foi licenciado com uma Licença Creative Commons Atribuição - NãoComercial - SemDerivados 3.0 Não Adaptada

http://dx.doi.org/10.22351/et.v58i1.3091

\title{
Mito E ACONTECIMENTO: AS RELAÇões ENTRE MitOlogia E HiSTÓRIA NAS TEORIas de Eliade e Girard ${ }^{1}$
}

\author{
Myth and historical event: the relations between myth and history \\ in Eliade and Girard's theories
}

\begin{abstract}
Vanderlei Dorneles ${ }^{2}$
Resumo: Este artigo parte do pressuposto da retomada dos mitos como textos da cultura a partir da segunda metade do século 20 para analisar as teorias dos filósofos Eliade e Girard em relação à ideia de acontecimento e tempo histórico conforme implicados nas narrativas míticas. O objetivo é compreender o conceito de acontecimento histórico que os autores têm em mente ao tratar com os eventos por trás dos textos mitológicos. O estudo é feito a partir de uma análise comparativa entre as ideias mais centrais dos autores em relação a mito e história. A análise permite propor um paralelo mínimo entre o "tempo primordial" de Eliade, como o momento original dos eventos míticos, e os "fatos históricos" de perseguição fundantes dos mitos segundo a visão de Girard.
\end{abstract}

Palavras-chave: Mito. Texto da cultura. Acontecimento histórico. Perseguição.

Abstract: This article starts from the assumption of the retaking of myths as texts of culture since the second half of the 20th century, to analyze the theories of the philosophers Eliade and Girard in relation to the idea of historical event and time as implied in the mythical narratives. The purpose is to comprehend the concept of historical event that the authors have in mind when they deal with the facts behind the mythological texts. The study is a comparative analysis between the authors' most central ideas regarding myth and history. The analysis allows presenting a minimum parallel between Eliade's "primordial time" as the original moment of the mythical events, and the "historical facts" of persecution as foundation of the myths according to Girard's view.

Keywords: Myth. Text of culture. Historical event. Persecution

1 O artigo foi recebido em 04 de agosto de 2017 e aprovado em 02 de outubro de 2017 com base nas avaliações dos pareceristas ad hoc.

2 Doutor em Ciências pela Escola de Comunicação e Artes (USP) e doutorando em Ciências da Religião pela Universidade Metodista de São Paulo. Atua como docente no Unasp-EC. Contato: vanderlei.dorneles@ ucb.org.br 


\section{Introdução}

Como narrativas das culturas tradicionais, os mitos têm sido redescobertos e recebido novas conceituações desde o início do século 20. Há um crescente interesse em investigá-los como representações das crenças e práticas culturais e religiosas dos povos que os desenvolveram e os rememoram em seus rituais. No entanto, apesar de os mitos receberem novas conceituações nas teorias literárias, o conceito de acontecimento e evento histórico implicado nos mitos permanece pouco definido. Em que consiste a relação do tempo primordial de Eliade e o tempo histórico? Como a teoria de Girard nos ajuda a entender a questão de tempo histórico presente nos mitos?

O objetivo deste artigo é tentar compreender essas questões a partir de uma análise comparativa entre esses dois importantes pensadores da segunda metade do século 20. Inicialmente se faz uma breve descrição da retomada do interesse pela mitologia, para em seguida se discutir as principais ideias de Eliade e Girard acerca da relação entre mitologia e tempo histórico.

\section{A redescoberta dos mitos}

Como textos da cultura, os mitos têm atraído a atenção de diversos pesquisadores, e suas definições se dividem em duas linhas: (1) os mitos são representações arcaicas desmistificadas na cultura moderna; e (2) os mitos são importantes representações para a compreensão das culturas arcaicas. Como representante da primeira concepção, predominante no século 19, Ernst Cassirer vê o mito como pensamento primitivo, ao afirmar que "a mitologia irrompe com maior força nos tempos mais antigos da história do pensamento humano", uma "obscura sombra que a linguagem projeta sobre o pensamento", a qual, contudo, não desaparecerá. ${ }^{3}$

$\mathrm{Na}$ segunda linha de abordagem, o filósofo italiano Gianni Vattimo discorda da associação entre mito e cultura primitiva e diz que a redescoberta contemporânea do mito exige sua redefinição. ${ }^{4}$ Os conceitos de mito predominantes até o século 19 estariam ultrapassados, tanto os de Cassirer como os de Lévi-Strauss, que não têm uma concepção puramente evolucionista, mas veem o mito "como destinado a desenvolver-se no logos". Para Vattimo, "o horizonte de uma concepção metafísica, evolutiva, da história" usado para ver o mito já não se justifica, e a concepção do mito como pensamento primitivo parece hoje "indefensável"s.

Numa abordagem mais funcional e existencialista dos mitos, Burkert os considera como "narrativas tradicionais" que ligam presente e passado e são, sobretudo, "estruturas de sentido". ${ }^{6}$ Nessa linha, Campbell considera que as narrativas mitológicas sempre deram "sustentação à vida humana", "construíram civilizações e enforma-

\footnotetext{
3 CASSIRER, Ernest. Linguagem e mito. 4. ed. São Paulo: Perspectiva, 2000. p. 19.

4 VATTIMO, Gianni. A sociedade transparente. Lisboa: Relógio D’Água, 1992. p. 37.

5 VATTIMO, 1992, p. 39.

6 BURKERT, Walter. Mito e mitologia. Lisboa: Edições 70, 2001. p. 18, 19, 32.
} 
ram religiões através dos séculos". Como ideias de base, esses arquétipos aparecem em todas as épocas sob "diferentes roupagens". ${ }^{7}$ Karen Armstrong diz que os povos antigos tinham dois modos de pensar, falar e adquirir conhecimento: o mythos e o logos. "O mito, considerado primário, refere-se ao que se julgava intemporal e constante em nossa experiência. Remontava às origens da vida, aos fundamentos da cultura, aos níveis mais profundos da mente humana". Ela acrescenta que o mythos de uma sociedade proporciona um contexto que atribui "sentido a seu cotidiano".

Mircea Eliade também vê os mitos na perspectiva de sua funcionalidade, em atribuir valor e status de realidade às ações humanas, na sua luta com o devir histórico. Eliade atesta que, ao longo do século 20, especialistas em mitologia passaram a situar o mito numa perspectiva bem diferente daquela do século 19. Em vez de "fábula, invenção e ficção", o mito passou a "história verdadeira" "sagrada" e "significativa".

Segundo esses autores, os mitos não são narrativas ilusórias, mas fontes de saber, da ordem do sentido da vida. Eles exercem uma importante função existencial e são parte do acervo da cultura. Assim, na abordagem mais difundida desde meados do século 20, os mitos são vistos como estruturas de sentido, que embora desafiem a mentalidade racionalista moderna, exercem uma função prática, no sentido de mediar as relações do ser humano com o mundo.

\section{Eliade: mito e tempo primordial}

Mircea Eliade e René Girard têm pontos de vista filosóficos e antropológicos bastante distintos. Eliade considera o ser humano religioso por natureza. Por isso sua antropologia se abre para uma "religiosidade universal" positiva. Por sua vez, Girard vê os seres humanos como naturalmente inclinados à rivalidade mimética e à violência, "um direcionamento talvez enraizado em seus baixos instintos de sobrevivência". Ambos também apresentam diferentes compreensões sobre a história em relação ao mito. Para Eliade, o mito é distinto do tempo histórico, uma vez que narra um evento histórico, mas ajustado aos arquétipos atemporais do tempo sagrado. Em contraste, a teoria de Girard implica uma história "linear e escatológica"10.

No entanto, uma vez que ambos trabalham com o conceito de evento histórico, é preciso saber que pontos de contato pode haver entre a visão deles acerca da relação entre mito e acontecimento.

O filósofo romeno Mircea Eliade (1907-1986), naturalizado americano, é considerado o pai da história das religiões e um dos mais importantes estudiosos das mitologias. Para ele, as mitologias colocam os seres humanos em contato direto com as realidades do sagrado e da origem do mundo. Sem os mitos, os seres humanos não

7 CAMPBELL, Joseph. O poder do mito. 25. ed. São Paulo: Palas Athena, 2007. p. 4, 5, 54, 62.

8 ARMSTRONG, Karen. Em nome de Deus: O fundamentalismo no Judaísmo, no Cristianismo e no Islamismo. São Paulo: Cia das Letras, 2001. p. 13.

9 ELIADE, Mircea. Aspectos do mito. São Paulo: Edições 70, 1963. p. 9, 11.

${ }^{10}$ BABUTS, Nicolae (ed.). Mircea Eliade: Myth, Religion, and History. New Brunswick, NJ: Transaction, 2014. e-book. 
poderiam encontrar um sentido para sua existência nem visualizar sua origem e o destino de suas vidas. Os mitos, para Eliade, são basicamente histórias das origens.

Em sua clássica definição, Eliade diz que "o mito conta uma história sagrada, relata um acontecimento que teve lugar no tempo primordial, o tempo fabuloso dos "começos". Nesse tempo primordial, "graças aos feitos dos Seres Sobrenaturais, uma realidade passou a existir". Os mitos contam a origem da realidade como um todo, como o mundo, o cosmo, mas também a origem de "um fragmento" do mundo, "uma ilha, uma espécie vegetal, um comportamento humano, uma instituição"11. Os mitos descrevem, portanto, "como uma coisa foi produzida, como começou a existir". Para Eliade, as narrativas míticas revelam a essência da realidade e, sem elas, os valores e os significados essenciais da condição humana permaneceriam "desconhecidos ou, pelo menos, compreendidos imperfeitamente" 12 .

Essa perspectiva da função existencial dos mitos reflete a própria experiência de Eliade. Ele manifestava uma "profunda inquietação sobre o ser e as questões mais essenciais da vida". Souza diz que foi na religião que ele descobriu "as categorias e reflexões próprias do humano". Ele acrescenta que, para Eliade, o equilíbrio espiritual, "condição fundamental para a criatividade, está na oscilação entre a pesquisa científica e a imaginação literáría". Por isso ele buscou em sua ontologia "transcender a história", considerada um terror para o ser humano no mundo. ${ }^{13}$

\section{Mito e realidade}

Em seus estudos, Eliade se interessou especialmente por aquilo que pode ser considerado verdadeiro e real na condição humana. Para ele, a realidade do mundo não se encontraria na ciência nem na filosofia, mas nas religiões e nos mitos. E esses deveriam ser buscados em sua condição "viva", ou seja, os mitos das sociedades que melhor os preservaram frente ao secularismo.

Eliade argumenta que o mito é uma "história sagrada" e, por isso, revela uma "história verdadeira", porque se refere sempre a "realidades"14. Considerar os mitos como falsificações do mundo ou ficções equivale a negar o próprio mundo que eles relatam. Ele afirma que “o mito cosmogônico é 'verdadeiro' porque a existência do Mundo está aí para o provar; o mito da origem da morte é também 'verdadeiro' porque a mortalidade do homem prova-o, e assim por diante". A narrativa mitológica atribui um significado a um acontecimento; é ela que "confere realidade aos acontecimentos" 15 . Nesse sentido, "realidade" é a condição do acontecimento uma vez integrado a uma estrutura mítica por meio de um relato.

11 ELIADE, 1963, p. 12-13.

12 SOUZA, Vitor Chaves de. Mircea Eliade e o pensamento ontológico arcaico. São Paulo: Factash, 2014. p. 116.

13 SOUZA, 2014, p. 256.

14 ELIADE, 1963, p. 13.

15 ELIADE, Mircea. O mito do eterno retorno. Lisboa: Edições 70, 2000. p. 104. 
De acordo com Eliade, diversas pesquisas mostraram que a recordação de um "acontecimento histórico ou de uma personagem autêntica" não permanece por mais de dois ou três séculos na memória popular. ${ }^{16}$ Essa fugacidade dos fatos históricos explica sua condição de irrealidade. Ele diz que a memória popular tem dificuldade em reter acontecimentos "individuais" e figuras "autênticas" porque esses não têm raízes na memória. Por isso a memória recorre a outras estruturas a fim de preservar o que é essencial: "categorias em vez de acontecimentos, arquétipos em vez de personagens históricas". Ao narrar os eventos ao modelo mitológico, as sociedades primitivas se "defendem" da história por atribuir aos acontecimentos históricos um "significado meta-histórico"17. Nesse caso, o mito é visto por Eliade como uma linguagem específica, capaz de atribuir de fato ao evento histórico um status de "realidade" ou atemporalidade. No entanto, mesmo após isso, o que jaz na origem do mito é um evento temporal.

Quando fala do "terror da história", Eliade se refere a esse aspecto insuportável do devir histórico no qual os acontecimentos instáveis não alcançam sentido nem realidade. Para ele, a "memória histórica", isto é, a memória dos acontecimentos, não se apresenta revestida da linguagem de um arquétipo, por isso é "insuportável", por ser "destituída de sentido" ". A narrativa dos acontecimentos, na repetição de um arquétipo, atribui a esses acontecimentos um sentido sobre-humano, inserindo-os no domínio das divindades e dos eventos sagrados. Nesse processo, o ser humano encontra um sentido para sua existência percebendo-a como parte da realidade dos Seres Sagrados. Eliade reafirma que "um objeto ou uma ação só se tornam reais na medida em que imitam ou repetem um arquétipo"19.

Apesar de enfatizar a funcionalidade dos mitos em atribuir sentido à existência, Eliade insiste na "realidade" dos fatos narrados neles. Para ele, de fato, "os mitos relatam não só a origem do Mundo, dos animais, das plantas e do homem, mas também de todos os acontecimentos primordiais em consequência dos quais o homem se transformou naquilo que é hoje, ou seja, um ser mortal, sexuado, organizado em sociedade". Assim, embora narrados na linguagem mítica e das estruturas arquetípicas, os acontecimentos primordiais são tão reais quanto os resultados dos mesmos: o mundo, a vida e a condição humana tais como os conhecemos hoje. "Se o Mundo existe, se o homem existe, foi apenas porque os Seres Sobrenaturais desenvolveram uma atividade criadora nas 'origens'."'20

Sobre a condição humana, Eliade afirma que o ser humano "é mortal, porque qualquer coisa se passou in illo tempore", e insiste que "se essa coisa não tivesse acontecido, o homem não seria mortal". Ele acrescenta ainda que "o mito da origem da morte conta o que aconteceu in illo tempore, e, relatando esse incidente, explica por que razão o homem é mortal" 21 . À luz disso, por mais remoto que seja o in illo

\footnotetext{
${ }^{16}$ ELIADE, 2000, p. 58.

17 ELIADE, 2000, p. 154.

18 ELIADE, 2000, p. 90.

19 ELIADE, 2000, p. 49.

${ }^{20}$ ELIADE, 1963, p. 17.

${ }^{21}$ ELIADE, 1963, p. 17.
} 
tempore dos acontecimentos primordiais, para Eliade, ele foi um tempo e seus resultados perduram até o tempo presente. Assim, uma conexão entre o chamado "tempo primordial" e o tempo histórico fica implícita na continuidade de seus efeitos na condição humana presente.

\section{Mito, repetição e tempo}

A compreensão mais geral é de que a teoria de Eliade acerca dos mitos é anti-histórica. Sua obra clássica é intitulada exatamente de $O$ Mito do Eterno Retorno (2000). A ideia do "eterno retorno", inspirada em Nietzsche, seria comum a todas as religiões arcaicas. "Tal retorno às origens torna as religiões cíclicas." 22 Nessa linha, Paul Tillich diz que a história antiga (grega) é "cíclica e circular", e somente nas tradições monoteístas, em especial a cristã, ela é "linear e teleológica", ${ }^{23}$ De fato, Eliade diz que "os hebreus foram os primeiros a descobrir o significado da história como epifania de Deus e esta concepção, como era de se esperar, foi retomada e desenvolvida pelo cristianismo"24. Em decorrência disso, Souza diz que "o judaísmo e o cristianismo perdem, portanto, a característica do eterno retorno" 25 .

Por causa disso, Babuts afirma que alguns críticos ${ }^{26}$ consideram as "estruturas religiosas" de Eliade como "atemporais e a-históricas", o que, porém, pode não ser o caso, como sugere a mencionada conexão entre o tempo primordial e o histórico. ${ }^{27}$ Além disso, a ideia do arquétipo como condição exclusiva para que o acontecimento histórico seja inserido numa estrutura atemporal deixa subentendido que o acontecimento assim narrado ocorreu num tempo histórico, do contrário não se trataria de um acontecimento. De fato, para Eliade, o conceito do "sagrado" está tão unido ao conceito de "tempo sagrado", que não se pode separar os dois. Nessa dimensão arquetípica, ele trabalha com um tipo diferente de tempo que tem uma existência ontológica. Porém esse tempo é aquele em que o acontecimento histórico é inserido somente após sua narratividade ao modelo mitológico. Babuts diz que "a ideia de que as estruturas de Eliade são a-históricas é igualmente incompleta, se não equivocada"28.

Enquanto as sociedades tradicionais consideram a história repetível, a concepção moderna afirma a natureza irreversível da história. De fato, Eliade entende que o acontecimento primordial, ou "ab origine" dos mitos, se repete, o que anularia o terror da história na mente arcaica. Ele afirma que "não há mito cosmogônico que não seja também uma história, visto que conta tudo o que se passou ab origine" ${ }^{29}$. Essa narrativa não é "história" na moderna acepção do termo: "a de acontecimentos irreversíveis

\footnotetext{
22 SOUZA, 2014, p. 108.

${ }^{23}$ Cf. SOUZA, 2014, p. 108.

${ }^{24}$ ELIADE, 2000, p. 118-119.

25 SOUZA, 2014, p. 108.

${ }^{26}$ Cf. ALLEN, Douglas. Myth and Religion in Mircea Eliade. New York: Routledge, 2002. p. 242.

27 BABUTS, 2014, e-book.

28 BABUTS, 2014, e-book.

${ }^{29}$ ELIADE, 1963, p. 28.
} 
e não repetíveis", mas "uma história exemplar que pode repetir-se". A repetição, porém, não anula o valor histórico do acontecimento assim narrado. Eliade se refere ao "tempo primordial" como o "tempo em que o acontecimento teve lugar pela primeira $v e z "{ }^{30}$. Tendo ocorrido uma "primeira vez", o acontecimento precisa ter assumido um lugar no tempo histórico, e sua repetição só ocorre por meio da narração do mito que o conta por meio de um rito ou texto. Portanto a repetição do acontecimento é virtual e apenas simbólica.

Nessa perspectiva, um tempo histórico como palco dos acontecimentos primordiais fica implícito na compreensão de Eliade acerca dos mitos. Sua ideia da repetição não parece contrariar essa sugestão, uma vez que a repetição do evento somente pode ocorrer por meio de sua rememoração no rito.

A discussão de Eliade com a noção de história de Hegel pode ainda ampliar a noção do "tempo primordial" como inserido na história. Para Hegel, "a história é 'livre' e sempre 'nova', ela nunca se repete" 31 . A essa história que não se repete, opõe Hegel a Natureza, na qual as coisas se reproduzem até o infinito. Nesse caso, a decisão de romper com a condição cíclica da natureza é que fundaria a história e a cultura. Eliade, no entanto, argumenta que "a humanidade [das sociedades tradicionais] se opôs por todos os meios à história", e questiona: "Poderemos daí concluir que durante todo esse período a humanidade se mantinha na 'Natureza', da qual não se separara ainda?" 32 . O ponto de Eliade aqui é: como poderia o ser humano das sociedades tradicionais resistir ao devir histórico se ele ainda fosse parte da natureza, não tendo consciência do fluxo da história?

Para Eliade, "ser" é viver $n a$ condição paradisíaca. Por meio do rito, o primitivo tenta manter sua conexão com o tempo em que "era", o tempo paradisíaco. A recusa da história é uma tentativa de preservar-se no tempo primordial. Ele argumenta ainda:

Tudo o que sabemos acerca das recordações míticas do "Paraíso" mostra-nos, pelo contrário, a imagem de uma humanidade ideal, gozando de uma beatitude e plenitude espirituais inalcançáveis na condição atual do "homem pecador". [...] Efetivamente, os mitos de vários povos aludem a uma época longínqua, em que os homens não conheciam nem a morte, nem o trabalho, nem o sofrimento, e tinham todos os recursos ao seu alcance. In illo tempore, os deuses desciam à Terra e misturavam-se com os homens; por seu turno, os homens podiam facilmente subir ao Céu. Um pecado ritual interrompeu a comunicação entre o Céu e a terra, e os deuses retiraram-se para os céus mais elevados. Desde então, os homens têm de trabalhar para comer e já não são imortais ${ }^{33}$.

Na perspectiva de Eliade, os "acontecimentos" narrados nos mitos, portanto, são tomados como fatos reais e históricos, embora eles estejam narrados na linguagem

${ }^{30}$ ELIADE, 1963, p. 24.

${ }^{31}$ ELIADE, 2000, p. 105.

${ }^{32}$ ELIADE, 2000, p. 105.

${ }^{33}$ ELIADE, 2000, p. 105-106. 
própria do mito e das estruturas arquetípicas, que os transforma em acontecimento sagrado, pertencente ao domínio do atemporal. Nessa linha, Misane e Priedite dizem que "da perspectiva da fenomenologia religiosa, não há diferença básica entre mito e história". Ambos são narrativas e ambos dizem "como a presente ordem veio a existir". Entretanto, uma diferença entre eles pode residir "no grau de fabulação", ou de mitologização. ${ }^{34}$

Waldron afirma que, em $O$ Mito do Eterno Retorno, Mircea Eliade mostra "como um acontecimento histórico se transforma em mito ao ser adaptado a estruturas narrativas e ao modelizar o evento histórico a formas míticas preexistentes" 35 . Ele diz que Hayden White, em The Tropics of Discourse and Metahistory (1985), "estudou como a própria escrita da história tomou formas narrativas que refletiam os limites ideológicos do autor e dos tempos em que foi escrita". Waldron argumenta também que Alejo Carpentier tomou eventos históricos do Caribe e da história americana e os ajustou a "estruturas cósmicas e míticas", modelizando esses eventos segundo um padrão europeu preestabelecido. Nesse processo, aspectos históricos são eliminados e outros enfatizados e mesmo ampliados, segundo o olhar ou a perspectiva de quem narrou a história. Nesses casos, segundo Waldron, "o evento histórico é gradualmente absorvido por estruturas cíclicas e míticas"36. Essas estruturas se colocam em paralelo com os arquétipos das mitologias. São estruturas de sentido que atribuem um valor memorial aos acontecimentos.

Assim, na teoria de Eliade, os mitos contam histórias das origens do mundo, dos povos e das culturas na linguagem própria dos arquétipos. Os acontecimentos históricos primordiais são narrados numa linguagem específica que os insere na dimensão do sagrado. A memória das culturas retém os acontecimentos somente na proporção em que são contados em termos de acontecimentos míticos, envolvendo deuses e heróis. A teoria de Eliade, nesse aspecto, apresenta certas aproximações com a de Girard.

\section{Girard: mito e perseguição}

O filósofo e historiador francês René Girard (1923-2015) desenvolveu uma teoria acerca dos mitos e sua relação com fatos históricos que se tornou bastante propagada desde o final do século 20. Ele analisa os mitos como relatos de eventos históricos relativos à fundação e diferenciação das culturas. Para ele, atos de violência marcam esses eventos e são narrados na forma de mitos, de maneira a dissimular ou esconder a violência factual. $\mathrm{O}$ pano de fundo de Girard não é a religião, mas a crítica

\footnotetext{
${ }^{34}$ MISANE, Agita; PRIEDITE, Aija. National Mythology in the History of Ideas in Latvia: A View from Religious Studies. In: HOSKING, Geoffrey; SCHÖPFLIN, George (Eds.). Myths and Nationhood. New York: Routledge, 1997. p. 161-162.

35 WALDRON, John V. The Fantasy of Globalism: The Latin American Neo-Baroque. Lanham, MD: Lexington, 2014. p. 35.

36 WALDRON, 2014, p. 35.
} 
literária. Mesmo assim, ele trabalha com a violência religiosa, ou seja, o "processo de vitimização com motivação religiosa" ${ }^{37}$.

O conceito do "bode expiatório" está no centro da teoria de Girard. Ele descreve esse mecanismo sociocultural como tendo quatro características principais. Nos eventos narrados nos mitos, para Girard, (1) as violências são reais, (2) a crise é real, (3) as vítimas são escolhidas não por causa de crimes que lhe sejam atribuídos, mas de suas marcas vitimárias, e (4) o sentido da operação é lançar sobre as vítimas a responsabilidade da crise e de eliminar tais vítimas da comunidade que elas "poluem". ${ }^{38}$

Como ponto de partida para sua teoria, Girard analisa o mito de Édipo, segundo o qual uma situação de crise se instala em Tebas, e a eliminação de um culpado se apresenta como a saída para o estado de desordem. A vítima a ser sacrificada é alguém que aparentemente cometeu crimes e que tem uma relação frágil com a comunidade. "Para eliminar a epidemia, afirma o oráculo, é preciso expulsar o abominável criminoso." No caso de Édipo, Girard descreve o que chama de marcas vitimárias: "Em primeiro lugar, temos a enfermidade: Édipo coxo. Por outro lado, este herói chegou a Tebas desconhecido de todos, estrangeiro de fato ou também de direito"39.

Contrariando correntes tradicionais na análise dos mitos, Girard propõe que os elementos imaginários nos textos mitológicos não são inventados por "literatos solitários", especialistas em elaborar narrativas e dramas ficcionais, nem pelo "inconsciente do sujeito psicanalítico", mas pelo "inconsciente dos perseguidores; o mesmo que inventa o infanticídio ritual dos cristãos no império romano e dos judeus no mundo cristão". Esses perseguidores agem coletivamente, e a causa se torna um plano geral para a solução da crise. "É a mesma imaginação que inventa a história dos rios envenenados durante a peste negra." 40

Girard conclui que o mito de Édipo não é um "texto literário" como tantos outros, nem um "texto psicanalítico", mas sem dúvida "um texto de perseguição", que esconde as reais razões dos atos perseguidores de sua comunidade por meio de uma linguagem criada no inconsciente da coletividade ${ }^{41}$ Assim, ele argumenta que o texto mitológico é uma narrativa de um evento real de perseguição, que, porém, esconde em sua linguagem própria essa dimensão real do fato. A fim de convencer os leitores da lógica de sua argumentação acerca das questões literárias da linguagem mítica capazes de esconder os fatos reais do evento persecutório, ele propõe uma versão alternativa do mito de Édipo, despida de sua linguagem mitológica:

As colheitas são ruins, as vacas abortam; ninguém se entende mais. Dir-se-ia que lançaram uma maldição sobre a aldeia. Foi o coxo, está claro que realizou o golpe. Ele chegou um dia, não se sabe de onde e se instalou como se estivesse em casa. Até se permitiu esposar a herdeira mais vistosa da aldeia e lhe fazer dois filhos. Parece que entre

\footnotetext{
37 BABUTS, 2014, e-book.

38 GIRARD, René. O bode expiatório. São Paulo: Paulus, 2004. p. 33.

39 GIRARD, 2004, p. 34.

40 GIRARD, 2004, p. 38.

${ }^{41}$ GIRARD, 2004, p. 39.
} 
eles tudo corre a mil maravilhas! Suspeitam que o estrangeiro tenha provocado o mal para o primeiro esposo de sua mulher, uma espécie de potentado local, desaparecido em circunstâncias misteriosas e um pouco demasiado depressa retomado em um ou outro papel pelo recém-chegado. Um belo dia os rapazes da aldeia se fartaram; tomaram seus forcados e forçaram o inquietante personagem a fugir ${ }^{42}$.

A linguagem parece contar uma história totalmente crível, numa sociedade cristã entre os séculos 12 e 19. No entanto, o que mudou foi somente a linguagem, os fatos são os mesmos. Assim, diz ele, "basta modificar ligeiramente a apresentação de um texto para inibir ou desencadear a única desmistificação verdadeiramente radical de que dispomos, e ninguém tem consciência desse estado de coisas".

Para fundamentar sua teoria, Girard também analisa o mito da fundação de Roma, com os irmãos gêmeos Remo e Rômulo em disputa. "Rômulo mata Remo e, ao fazer isso, funda Roma e se torna seu primeiro rei." O tema dos “irmãos rivais" é muito comum nos mitos universais. Para Girard, esse tema é uma representação mítica da duplicação mimética e da indiferenciação trazidas pela intensificação da mimese da rivalidade. "O mito, nesse sentido, representa o traço do evento real, embora a representação do evento em si tenha sido desfigurada em sua narrativa." ${ }^{43}$

Sobre a situação de crise, Girard diz que um estado de desordem e indiferenciação torna-se patente: "O dia e a noite se confundem. O céu e a Terra se comunicam: os deuses circulam entre os homens e os homens entre os deuses. Entre o deus, o homem e o animal não há nítida distinção. O Sol e a Lua são irmãos gêmeos; lutam entre si perpetuamente e não conseguimos distingui-los" ${ }^{44}$. Curiosamente, essa é uma situação bem semelhante à descrita por Eliade em relação ao mundo antes da ocorrência do fato que lança a humanidade na condição caída. ${ }^{45}$

A ideia-chave, segundo Girard, na definição de uma situação de crise, que precede a perseguição, é a de indistinção ou indiferenciação. "As grandes crises sociais que favorecem as perseguições coletivas são vividas como uma experiência de indiferenciação." A indistinção "primordial”, o caos "original”, "tem frequentemente caráter fortemente conflitual". Segundo ele, "os indistintos não param de lutar entre si para se distinguir uns dos outros". Nessa busca por diferenciação nascem as culturas e as estruturas sociais, como resultado do fortalecimento dos vínculos e laços de pertença coletiva entre seus membros em decorrência da perseguição coletiva ao "bode expiatório". ${ }^{46}$

O projeto do mitólogo, na perspectiva da teoria de Girard, portanto, consiste em ler os mitos e desvendar sua linguagem, processo em que as narrativas são despidas da aparente "sacralidade" para revelar os eventos históricos reais que ocultam.

42 GIRARD, 2004, p. 41.

${ }^{43}$ FLEMING, Chris. Mimesis, Violence, and the Sacred: An Overview of the Thought of René Girard. In: COWDELL, Scott et al. (eds.). Violence, Desire, and the Sacred: René Girard and Sacrifice in Life, Love, and Literature. Londres: Bloomsbury, 2015. e-book.

44 GIRARD, 2004, p. 43.

45 ELIADE, 2000, p. 105-106.

46 GIRARD, 2004, p. 43. 
Segundo ele, "todos os crimes que os perseguidores atribuem a suas vítimas reaparecem, como regra geral, nos mitos" ${ }^{\prime 4}$. Ele analisa diversas narrativas antigas e conclui que todas ou pelo menos uma grande maioria pode ser lida a partir dessa teoria geral.

\section{Sobre os monstros}

Um dos artifícios de linguagem mitológica é a construção de figuras monstruosas, as quais são combatidas e, em geral, vencidas por heróis igualmente construídos. Girard propõe que tais figuras sejam lidas como uma espécie de texto híbrido. Ele afirma que, "desde o romantismo, tendemos a ver no monstro mitológico uma verdadeira criação ex nihilo, uma pura invenção", o que não deve ser o caso. "Interpretamos a imaginação como poder absoluto de conceber formas que não existem em nenhum lugar na natureza." ${ }^{48}$ No entanto, o exame dos monstros mitológicos não revela nada disso. Elementos da condição de natureza são integrados a elementos da condição de cultura ou humanidade para formar as figuras monstruosas. Kearney diz que, ao retratar o Minotauro como um "estrangeiro criminoso de bestialidade indizível", o perseguidor planejava projetar a culpa moral por uma crise particular em "um estrangeiro cuja deformidade física sugeria uma afinidade com o monstro" $"$. Tritten diz que "muitos de alguma forma elegem seu Leviatã do estado de natureza" 50 .

Girard explica que, no processo de mitologização, os monstros devem resultar de uma fragmentação do que foi percebido pela comunidade, de uma decomposição seguida de uma recomposição que não leva em conta as particularidades naturais. Assim, "o monstro é uma alucinação instável que tende retrospectivamente a se cristalizar em formas estáveis, em falsas especificidades monstruosas" $"$. O monstro, nessa perspectiva, resulta de uma virtual percepção coletiva do mal por trás da crise. Ele afirma que as concepções de deformidade moral e física, supostamente causadoras da crise, se fundem na criação da figura monstruosa. ${ }^{52}$

Descontruídas as figuras monstruosas das narrativas míticas como representação das vítimas, Girard afirma que a análise dos mitos nos leva a "postular violências reais e vítimas reais por trás de temas tão fantásticos que pareceria quase inconcebível não mais considerá-los um dia como 'pura e simplesmente imaginários" ${ }^{\text {"53. }}$. Retomando a incidência dos textos de perseguição na história, ele lembra que as comunidades medievais levavam a sério "as fábulas mais dementes, os envenenamentos de fontes pelos judeus ou pelos leprosos, infanticídios rituais, as vassouras das feiticeiras, as orgias diabólicas à luz do luar". Girard afirma que o fenômeno do "bode expiatório

47 GIRARD, 2004, p. 44.

${ }^{48}$ GIRARD, 2004, p. 46.

${ }^{49}$ KEARNEY, Richard. Strangers, Gods and Monsters: Interpreting Otherness. New York: Routledge, 2003. p. 45.

${ }^{50}$ TRITTEN, Tyler. Beyond Presence: The Late F. W. Schelling's Criticism of Metaphysics. Berlin: De Gruyter, 2012. p. 264.

${ }^{51}$ GIRARD, 2004, p. 47.

${ }^{52}$ GIRARD, 2004, p. 47, 49.

${ }^{53}$ GIRARD, 2004, p. 51-52. 
designa simultaneamente a inocência das vítimas, a polarização coletiva que se efetua contra elas e a finalidade coletiva dessa polarização" 54 .

No livro bíblico de Levítico, de onde Girard toma o conceito do "bode expiatório", o bode é um animal de sacrifício. Ele é uma vítima escolhida para portar a culpa coletiva. A morte do bode é vista como condição para a expiação, para que os pecados de Israel sejam levados da comunidade, visualizando-se uma condição de restauração coletiva da ordem social. No processo do bode expiatório, "o transgressor se transforma em restaurador e até em fundador da ordem que ele de algum modo havia antecipadamente transgredido" 55 . Curiosamente, "os bodes expiatórios não curam, sem dúvida, nem as verdadeiras epidemias, nem as secas, nem as inundações". No entanto, Girard explica que a dimensão principal de toda crise é o modo pelo qual ela atinge as "relações humanas", e são essas relações que são virtualmente curadas mediante a morte do bode expiatório. ${ }^{56}$

Portanto, segundo a visão de Girard, o fenômeno do "bode expiatório" ou o "mecanismo da vítima solitária" está intimamente ligado com a origem de uma cultura ou civilização. Babuts explica que esse mecanismo se encontra "codificado na fundação dos mitos das culturas" ${ }^{57}$. No entanto, uma vez que são herdados de geração em geração e se desdobram em variadas versões, os mitos também "dissimulam o assassinato fundador, o evento do bode expiatório original no qual a cultura é fundada". Girar chama isso de "cristalização mítica" 58 . Ao longo do tempo, essa cristalização mítica "distorce, lava ou dissimula" os eventos históricos extratextuais do assassinato fundador. ${ }^{59}$

\section{Mito e história}

Para Girard, os mitos originam-se de fatos reais e históricos. Segundo Kearney, Girard considera como mito "qualquer narrativa que contenha essas características sacrificiais" $" 60$. Todo texto que conta uma violência sacrificial contra uma vítima enquanto busca cobrir seu próprio mecanismo perseguidor é um mito. Além disso, "Girard vai mais longe ao declarar que mitos sacrificiais se referem não somente a desejos inconscientes de perseguir, mas a eventos reais". Não se trata de "atos simbólicos ou imaginários de violência, mas de narrativas enraizadas em fatos históricos dissimulados" na linguagem mitológica. Kearney enfatiza ainda que Girard resiste a qualquer sugestão de que os mitos sacrificiais possam ser reduzidos a algum jogo "intertextual" de relações linguísticas, como alguns pós-estruturalistas ou desconstrucionistas propõem. Eles também não se relacionam a meras "estruturas" mentais, como reivindi-

\footnotetext{
54 GIRARD, 2004, p. 55.

55 GIRARD, 2004, p. 59.

56 GIRARD, 2004, p. 60-61.

57 BABUTS, 2014, e-book.

58 GIRARD, 2004, p. 88-94.

59 BABUTS, 2014, e-book.

${ }^{60}$ KEARNEY, 2003, p. 43.
} 
cam antropologistas culturais como Lévi-Strauss ou Dumézil. Eles se referem, insiste Girard, a eventos históricos de vitimização.

Embora não sejam relatos precisos, mas "distorcidos", dos eventos, os mitos narram eventos históricos. Para Girard, a tendência dos intérpretes modernos em considerar os mitos como "pura ficção sem base real" produz má interpretação dos mitos e má compreensão acerca de suas origens históricas. ${ }^{61}$

Nessa perspectiva, Tritten diz que, a exemplo de Schelling, René Girard também aponta o mito como o elemento diferenciador das culturas e dos povos. No entanto, ele enfatiza que Girard vê "a origem do mito como um acontecimento dentro da história legalizado por uma aparentemente já dada coletividade, a unanimidade que se origina da violência coletiva contra uma vítima arbitrária, substituta" ${ }^{62}$. A unanimidade do ato forma a coletividade de um povo.

Na teoria de Girard, a leitura dos mitos é grandemente determinada pela perspectiva adotada frente aos mesmos. Golsan diz que, uma vez que tendemos a considerar os mitos como "narrativas superiores, ficções poéticas que de alguma forma são mais elevadas que as realidades banais da história", e uma vez que geralmente sabemos bem pouco acerca das culturas que os produziram, "nós falhamos em aplicar aos mitos os mesmos rigorosos princípios de análise que costumamos aplicar aos textos históricos". O resultado desse "respeito cerimonioso" é que falhamos em ver o que os mitos realmente comunicam em termos de história e acontecimento. ${ }^{63}$

Assim, os atos de violência coletiva, ou atos de sacrifício, contra vítimas inocentes estão na origem dos mitos, segundo a teoria de Girard. A ordem cultural emerge dos mesmos ou é renovada por meio deles. Em termos simplificados, o sacrifício fundador na origem das culturas é "o mecanismo gerador de todas as mitologias". Nesse sentido, o projeto do estudo das mitologias é o de retomar "as crises e o sacrifício fundador", a sequência dos eventos históricos que constituíram ou reconstituíram a ordem cultural. ${ }^{64}$

Kearney afirma que, para Girard, "se os mitos são de fato ficcionais em algum aspecto, é em sua capacidade formal de camuflar a gênese dos sinais sacrificiais dos atos históricos de perseguição"65. Ao analisar a repetição do mito no rito, Girard considera que "a função especial de um rito religioso é manter a paz alcançada por meio do bode expiatório ao institucionalizar uma repetição dele no sacrifício", ao mesmo tempo em que essa repetição serve para dissimular sua realidade histórica. Para Girard, a forma textual dessa cobertura é o que ele caracteriza como "mito"66.

Portanto, para Girard, os mitos são a "transfiguração retrospectiva de crises sacrificiais, a reinterpretação dessas crises à luz da ordem cultural que tem emergido delas". Entretanto, embora os mitos frequentemente tentem "manter em segredo" a

\footnotetext{
${ }^{61}$ GOLSAN, Richard J. An Introduction to René Girard and Myth. New York: Routledge, 2002. p. 62.

62 TRITTEN, 2012, p. 264.

${ }^{63}$ GOLSAN, 2002, p. 65.

${ }^{64}$ GOLSAN, 2002, p. 62.

65 KEARNEY, 2003, p. 44.

${ }^{66}$ FLEMING, 2015, e-book.
} 
violência que subjaz em sua origem, eles invariavelmente deixam pistas suficientes para identificação por aqueles que são suficientemente inquisitivos em sua leitura do texto mitológico. ${ }^{67}$

\section{Conclusões}

A retomada do interesse pelas narrativas mitológicas desde a segunda metade do século 20 possibilitou o surgimento de novas conceituações do mito, distanciando-se da visão tradicional em que os mitos eram vistos como estágio primitivo das culturas. Segundo as teorias mais recentes, as narrativas míticas são substrato da cultura de todos os povos. Os mitos continuam vivos nas culturas mais primitivas e recebem novas configurações nas sociedades modernas. Eles são vistos como estruturas narrativas portadoras de um significado mais profundo para o mundo e a vida humana.

Entre os diversos teóricos do mito, destacam-se Mircea Eliade e René Girard, os quais demonstraram grande interesse em entender os mitos e sua relação com a vida prática das sociedades que os desenvolveram. A análise comparativa das teorias de Eliade e Girard acerca de mito e história permite afirmar que ambos têm um conceito de evento e tempo histórico implicado nas narrativas mitológicas que não parece inteiramente desconectado do tempo presente ou profano. Eliade afirma que os eventos do "tempo primordial" revelados nas narrativas míticas determinam a realidade e as condições da vida presente. Por sua vez, Girard propõe que as narrativas míticas tratam com eventos reais e históricos, embora os relate numa linguagem específica que tende a dissimular e esconder os mesmos.

Tanto Eliade como Girard, apesar de perspectivas distintas, consideram os mitos como histórias de fatos "reais". Entretanto, uma vez que a linguagem da mitologia tende a modelizar esses eventos segundo estruturas arquetípicas ou escondê-los numa linguagem não objetiva, eles precisam ser redescobertos mediante o despir as narrativas de sua linguagem própria. Os eventos históricos, nesse caso, precisam ser desvendados através dos labirintos dos textos míticos. Para Eliade, o que se descobre são ações de Seres Sagrados, ao passo que Girard afirma encontrar as pistas de atos de perseguição e crueldade próprios de seres demasiado humanos.

\section{Referências}

ALLEN, Douglas. Myth and Religion in Mircea Eliade. New York: Routledge, 2002.

ARMSTRONG, Karen. Em nome de Deus: O fundamentalismo no Judaísmo, no Cristianismo e no Islamismo. São Paulo: Cia da Letras, 2001.

BABUTS, Nicolae (ed.). Mircea Eliade: Myth, Religion, and History. New Brunswick, NJ: Transaction, 2014.

BURKERT, Walter. Mito e mitologia. Lisboa: Edições 70, 2001.

CAMPBELL, Joseph. O poder do mito. 25. ed. São Paulo: Palas Athena, 2007.

CASSIRER, Ernst. Linguagem e mito. 4. ed. São Paulo: Perspectiva, 2000.

${ }^{67}$ FLEMING, 2015, e-book. 
ELIADE, Mircea. Função do Mito. In: . O Poder do Mito. São Paulo: Martin Claret, 2008. . Aspectos do mito. São Paulo: Edições 70, 1963.

. O mito do eterno retorno. Lisboa: Edições 70, 2000.

FLEMING, Chris. Mimesis, Violence, and the Sacred: An Overview of the Thought of René Girard. In: COWDELL, Scott et al. (eds.). Violence, Desire, and the Sacred: René Girard and Sacrifice in Life, Love, and Literature. Londres: Bloomsbury, 2015.

GIRARD, René. O bode expiatório. São Paulo: Paulus, 2004.

GOLSAN, Richard J. An Introduction to René Girard and Myth. New York: Routledge, 2002.

KEARNEY, Richard. Strangers, Gods and Monsters: Interpreting Otherness. New York: Routledge, 2003.

MISANE, Agita; PRIEDITE, Aija. National Mythology in the History of Ideas in Latvia: A View from Religious Studies. In: HOSKING, Geoffrey; SCHÖPFLIN, George (Eds.). Myths and Nationhood. New York: Routledge, 1997.

SOUZA, Vitor Chaves de. Mircea Eliade e o pensamento ontológico arcaico. São Paulo: Factash, 2014.

TRITTEN, Tyler. Beyond Presence: The Late F. W. Schelling's Criticism of Metaphysics. Berlin: De Gruyter, 2012.

VATTIMO, Gianni. A sociedade transparente. Lisboa: Relógio D’Água, 1992.

WALDRON, John V. The Fantasy of Globalism: The Latin American Neo-Baroque. Lanham, MD: Lexington, 2014.

WHITE, Hayden. The Tropics of Discourse: Essays in Cultural Criticism. Baltimore: Johns Hopkins University Press, 1985. 